\title{
Acetylcarnitine potentiates the anticarcinogenic effects of butyrate on SW480 colon cancer cells
}

\author{
IHSAN ELIMRANI $^{1 *}$, SERGE DIONNE $^{1 *}$, DAN SARAGOSTI $^{1}$, IJAZ QURESHI $^{2}$, \\ EMILE LEVY $^{2}$, EDGAR DELVIN $^{2}$ and ERNEST G. SEIDMAN ${ }^{1}$
}

\author{
${ }^{1}$ Division of Gastroenterology, Research Institute, McGill University Health Center, Faculty of Medicine, \\ McGill University; ${ }^{2}$ Sainte Justine Hospital Research Center, Departments of Nutrition \\ and Biochemistry, University of Montreal, Montreal, Quebec, Canada
}

Received December 13, 2014; Accepted February 2, 2015

DOI: $10.3892 / \mathrm{ijo} .2015 .3029$

\begin{abstract}
Butyrate is a potent anticarcinogenic compound against colon cancer cells in vitro. However, its rapid metabolism is hypothesized to limit its anticancer benefits in colonic epithelial cells. Carnitine, a potent antioxidant, is essential to fatty acid oxidation. The aims of this study were to identify a colon cancer cell line capable of transporting carnitine. We evaluated the effect of carnitine and acetylcarnitine (ALCAR) on the response of colon carcinoma cells to butyrate. We explored the mechanisms underlying the anticarcinogenic benefit. SW480 cells were incubated with butyrate \pm carnitine or ALCAR. Carnitine uptake was assessed using $\left[{ }^{3} \mathrm{H}\right]$-carnitine. Apoptosis and cell viability were assessed using an ELISA kit and flow cytometry, respectively. Modulation of proteins implicated in carnitine transport, cell death and proliferation were assessed by western blotting. SW480 cells were found to transport carnitine primarily via the OCTN2 transporter. Butyrate induced SW480 cell death occurred at concentrations of $2 \mathrm{mM}$ and higher. Cells treated with the combination of butyrate $(3 \mathrm{mM})$ with ALCAR exhibited increased mortality. The addition of carnitine or ALCAR also increased butyrateinduced apoptosis. Butyrate increased levels of cyclin D1, p21 and PARP p86, but decreased Bcl- $X_{\mathrm{L}}$ and survivin levels. Butyrate also downregulated dephospho- $\beta$-catenin and increased acetylated histone $\mathrm{H} 4$ levels. Butyrate and carnitine decreased survivin levels by $\geq 25 \%$. ALCAR independently induced a $20 \%$ decrease in $\mathrm{p} 21$. These results demonstrate that butyrate and ALCAR are potentially beneficial anticarcinogenic nutrients that inhibit colon cancer cell survival in vitro. The combination of both agents may have superior anticarcinogenic properties than butyrate alone.
\end{abstract}

Correspondence to: Dr Ernest G. Seidman, Research Institute, McGill University Health Center, MGH Campus, C10.145, 1650 Cedar Avenue, Montreal, Quebec H3G 1A4, Canada

E-mail: ernest.seidman@mcgill.ca

Key words: OCTN2, Caco-2 cells, cell death, cell apoptosis, cell cycle progression proteins

\section{Introduction}

Butyrate is a short-chain fatty acid that plays a key role in maintaining intestinal homeostasis. It is principally derived from ingested dietary fiber and dairy products and is formed in the colon as a result of fermentation by anaerobic bacteria $(1,2)$. Butyrate is the principal oxidative fuel for colonic epithelial cells, unlike other cells that use glucose and has long been regarded as a potential neutriceutical anticarcinogen (3). Butyrate has been shown to reduce the growth and motility of colon cancer cell lines, as well as inhibit proliferation and induce apoptosis in vitro $(4,5)$. Inhibition of histone deacetylases (HDAC) plays an important role in the anticarcinogenic properties of butyrate (6). When present in sufficient amounts butyrate and HDAC inhibitors reactivate the transcription of silenced genes and increase differentiation and apoptosis in cancer cells (6).

L-carnitine ( $\beta$-hydroxy- $\gamma$-trimethylaminobutyrate) is a non-essential amino acid synthesized from methionine and lysine in the liver, kidney and brain. Principally derived from the diet, L-carnitine is absorbed in the intestine and transferred to other tissues by recognized transporters. Carnitine plays an important role in lipid metabolism, in the $\beta$-oxidation of fatty acids, and consequently in the production of cellular energy (7). Carnitine facilitates the transport of long-chain fatty acids across the mitochondrial inner membrane as acylcarnitine esters (8). Free carnitine is available in equilibrium with acetyl L-carnitine (ALCAR) due to the ubiquitous presence of carnitine acetyltransferase, which also produces other short chain acylcarnitines, including butyrylcarnitine (9).

Previous study in our lab reported that carnitine inhibited the development of precancerous lesions and macroscopic colonic tumors in AOM-treated C57BL/6J mice (10). We also found a positive effect of carnitine on butyrate-induced Caco-2 colon carcinoma cell death (11). However, further analysis of the beneficial effects of carnitine was limited by its poor uptake in vitro. Carnitine transport was very limited in undifferentiated Caco- 2 cells, a well established model of colon cancer, compared to differentiated Caco-2 cells, a model of small intestinal absorptive epithelial cells. We previously reported that undifferentiated Caco-2 cells express negligible levels of the carnitine transporter OCTN2 (12). We hypothesized that 
using a cell line with more efficient carnitine transport would likely increase the beneficial effects of carnitine and ALCAR alone or in combination with butyrate.

SW480 is a human colon adenocarcinoma cell line that has been used as an in vitro model for colorectal cancer to study tumor markers and biochemistry of tumorigenicity $(13,14)$. In this study, we first identified SW480 as a colon cancer cell line with relatively high carnitine uptake. We then determined the effect of carnitine and ALCAR on cancer cell death and apoptosis, and evaluated possible synergism with butyrate. We also investigated the mechanisms underlying the beneficial effects by examining proteins implicated in pathways important for cell proliferation and survival.

\section{Materials and methods}

Cell culture. SW480 and Caco-2 human colon cancer cell lines were obtained from the American Type Culture Collection (Manassas, VA, USA). SW480 cells were grown in RPMI medium (Gibco-BRL, Grand Island, NY, USA) containing $10 \%$ FBS. Caco-2 cells, at passage 17, were grown in MEM supplemented with decomplemented $10 \%$ FBS, penicillin/ streptomycin 1\%, and DMEM non-essential amino acid solution (all from Gibco-BRL). Both cell lines were grown in 75- $\mathrm{cm}^{2}$ plastic flasks (Corning Glass Works, Corning, NY, USA) and maintained at $37^{\circ} \mathrm{C}$ in a $95 \%$ air $-5 \% \mathrm{CO}_{2}$ atmosphere. After confluence (70-90\%), cells were split by using $0.05 \%$ trypsin $(0.5 \mathrm{nM})$ in EDTA (Gibco-BRL).

Carnitine uptake in colon cancer cells. Carnitine uptake studies were carried out according to the method of McCloud et al (15), with minor modifications as reported in our previous study (12). SW480 cells (between passages $108-110)$ were plated $\left(5 \times 10^{6} \%\right.$ well) onto 12-well plates (Corning Glass Works) in RPMI medium containing 5\% FBS. Cells were incubated in $1 \mathrm{ml}$ of pre-warmed Krebs-Ringer phosphate buffer (in mM: $123 \mathrm{NaCl}$, $4.93 \mathrm{KCl}, 1.23 \mathrm{MgSO}_{4}, 0.85 \mathrm{CaCl}_{2}, 5$ glucose, 5 glutamine, and $20 \mathrm{NaH}_{2} \mathrm{PO}_{4}$ ), at $\mathrm{pH}$ 7.4. Methyl-L- $\left[{ }^{3} \mathrm{H}\right]$-carnitine (Amersham Pharmacia Biotech, Buckinghamshire, UK) was added at a concentration of 50, 100 or $5 \mathrm{mM}$. After different incubation periods, the medium was aspirated and cells were immediately washed with ice-cold phosphate buffer and digested at $70^{\circ} \mathrm{C}$ with $0.5 \mathrm{ml}$ of $1 \mathrm{~N} \mathrm{NaOH}$. The reaction was neutralized after $1 \mathrm{~h}$ by adding $0.5 \mathrm{ml}$ of $1 \mathrm{~N} \mathrm{HCl}$. The cells were then collected, scintillation liquid was added, and radioactivity counted. In other series of experiments, higher concentrations of methyl$\mathrm{L}-\left[{ }^{3} \mathrm{H}\right]$-carnitine, as well as $\mathrm{Na}^{+}$, and $\mathrm{Cl}^{-}$dependence of the transport were tested. Furthermore, the effect of the amino acid transporter $\left(\mathrm{ATB}^{0+}\right)$ substrates on carnitine uptake, such as glycine, lysine and tryptophan (500 $\mu \mathrm{M}$ and $1 \mathrm{mM})$, was examined. All the experiments were conducted at $37^{\circ} \mathrm{C}$.

Effect of inhibitors on carnitine transport by SW480 cells. For this set of experiments, confluent SW480 were pre-incubated for 30 min with $500 \mu \mathrm{M}$ D-carnitine, pyrilamine, tetraethylammonium bromide (TEA), or valproate. These drugs were all purchased from Sigma (St. Louis, MO, USA).

Western blot analysis of OCTN2. Rabbit polyclonal antibodies were raised against a synthetic polypeptide from Research
Genetics (Huntsville, AL, USA), 5-QWQIQSQTRMQKDGEE SPT-3, corresponding to amino acids 532-550 of mouse OCTN2 (16). SW480 cells, undifferentiated (subconfluent) and mature (10-15 days post-confluence) were tested. The cells were washed, lysed and sonicated for $20 \mathrm{sec}$ in ice-cold lysis buffer (50 mM Tris, $150 \mathrm{mM} \mathrm{NaCl}, 10 \mathrm{mM}$ ethylenediaminetetraacetic acid, $1 \%$ Triton $\mathrm{X}-100)$ containing a mixture of protease inhibitors (Roche Diagnostics, Indianapolis, IN, USA). After determination of protein concentrations using the Micro BCA Protein Assay Reagent kit (Pierce, Rockford, IL, USA), samples were added to sample buffer [4\% SDS, 20\% glycerol, $200 \mathrm{mM}$ DTT, $120 \mathrm{mM}$ Tris (pH 6.8), and $0.002 \%$ bromophenol blue] and denatured in a boiling water bath for $5 \mathrm{~min}$. Samples were then separated by electrophoresis on a 7.5\% SDS-PAGE. The proteins were transferred to a polyvinylidene difluoride (PVDF) Immobilon membrane (Millipore, Bedford, MA, USA). The PVDF membrane was then incubated in PBS buffer containing 5\% skim milk. Subsequently, the membranes were incubated overnight with OCTN2 polyclonal anti-peptide antibody $(12,17)$, then incubated with a secondary, goat anti-rabbit IgG, horseradish peroxidase-linked whole antibody (Sigma). The membranes were washed and the ELISA substrate added (Boehringer Mannheim, Laval, QC, Canada). Molecular weights were estimated by using pre-stained SDS-PAGE broad-range standards (Bio-Rad, Hercules, CA, USA).

Cell death and apoptosis detection assays. SW480 cells were cultured as described above, and once sub-confluence was reached, stimulated with various concentrations of Na-butyrate (2 and $3 \mathrm{mM}$ ), alone or combined with carnitine $(5 \mathrm{mM})$ or ALCAR $(5 \mathrm{mM})$ for $48 \mathrm{~h}$. The cells were then stained with propidium iodide (PI) and cell death was verified by flow cytometry (FACScan, Becton-Dickinson, Mississauga, ON, Canada). In parallel, the ApoStrand Enzyme-linked Immunosorbent Assay Apoptosis Detection kit (Biomol Research Laboratories Inc., Plymouth, PA, USA) was employed to quantify the number of apoptotic cells with single-strand DNA breaks.

Western blot analysis of proteins implicated in cell cycle control and apoptosis. Western blotting was employed to monitor changes in the levels of acetyl histone H4, p21, dephosphorylated $\beta$-catenin, survivin, cyclin D1, PARP p89 and Bcl-X $\mathrm{X}_{\mathrm{L}}$. SW480 cells were treated with butyrate $(2$ and $3 \mathrm{mM})$ and carnitine $(5 \mathrm{mM})$ or ALCAR $(5 \mathrm{mM})$ for $48 \mathrm{~h}$. Lysates were prepared using an ice-cold lysis buffer containing a mixture of protease inhibitors (as described above). After determination of protein concentrations using the Micro BCA Protein Assay Reagent kit, equivalent samples $(40 \mu \mathrm{g})$ were resolved using 10 and $15 \%$ sodium dodecylsulfate polyacrylamide gel electrophoresis and then transferred to PVDF membrane Immobilon. Membranes were blocked in 5\% non-fat milk for $1 \mathrm{~h}$ and then incubated with acetyl histone $\mathrm{H} 4$ (Upstate Biotechnology Corp., Waltham, MA, USA), dephosphorylated $\beta$-catenin (Alexis, San Diego, CA, USA), phosphorylated p65 (Pharmingen, San Diego, CA, USA), p21 (Santa Cruz, CA, USA), survivin (Santa Cruz), cyclin D1 (Santa Cruz),

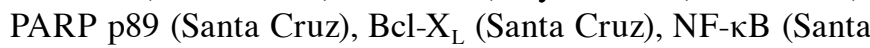
Cruz), and $\beta$-actin (Santa Cruz) primary antibodies at $4^{\circ} \mathrm{C}$ overnight. After washing with Tris-buffered saline/Tween-20, 

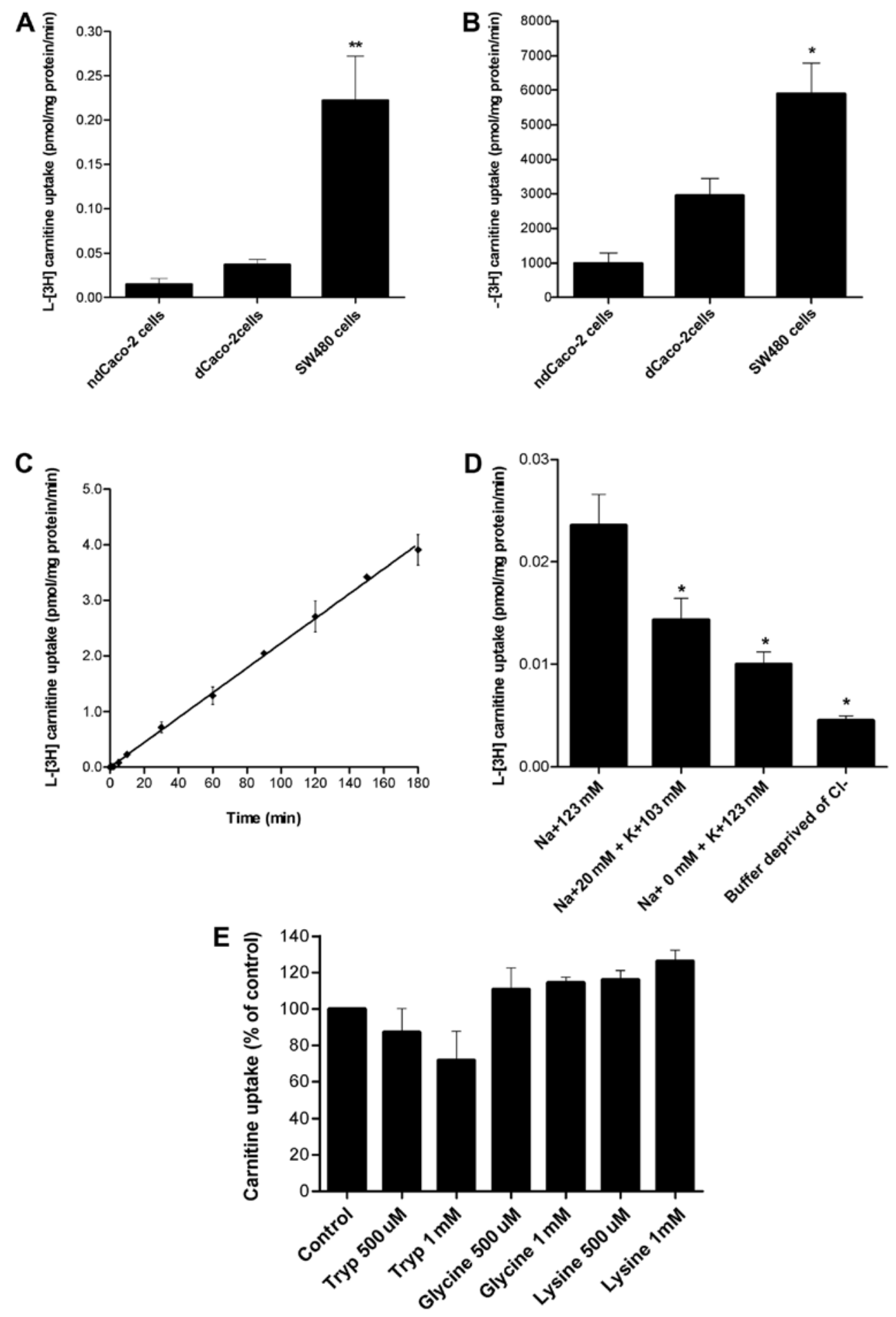

Figure 1. SW480 cell uptake of carnitine. $\mathrm{L}-\left[{ }^{3} \mathrm{H}\right]$-carnitine uptake was investigated in SW480 as well as in differentiated and non-differentiated Caco-2 cells Transport occured with $100 \mathrm{nM}(\mathrm{A})$ and $5 \mathrm{mM}$ (B) L- $\left[{ }^{3} \mathrm{H}\right]$-carnitine. SW480 cell uptake of L- $\left[{ }^{3} \mathrm{H}\right]$-carnitine was measured as a function of time (C) in KrebsRinger phosphate buffer containing varying concentrations of $\mathrm{Na}^{+}$and absence of $\mathrm{Cl}^{-}(\mathrm{D})$ and in the presence of $500 \mu \mathrm{M}$ and $1 \mathrm{mM}$ of tryptophane, glycine and lysine, as $\mathrm{ATB}^{0+}$ inhibitors (E). Cells were grown in $75-\mathrm{cm}^{2}$ plastic flasks in RPMI (for SW480) or DMEM (for Caco-2) medium supplemented with $10 \%$ FBS and they were maintained at $37^{\circ} \mathrm{C}$ in a $95 \%$ air $-5 \% \mathrm{CO}_{2}$ atmosphere. After confluence (70-90\%), the SW480 and Caco-2 cells were plated (5x105/well) onto 12 -well plates in medium supplemented with $5 \%$ FCS. Cells were incubated at $37^{\circ} \mathrm{C}$ with Krebs-Ringer phosphate buffer at pH 7.4 in the presence of 50,100 and $5 \mathrm{mM} \mathrm{L}-\left[{ }^{3} \mathrm{H}\right]$-carnitine. Each value represents the mean $\pm \mathrm{SE}$ of three separate experimentations. ${ }^{*} \mathrm{p}<0.05 .{ }^{* *} \mathrm{p}<0.01$.

membranes were incubated with the corresponding peroxidase-conjugated secondary antibody, anti-goat or anti-rabbit immunoglobulin $\mathrm{G}$, for $1 \mathrm{~h}$, and then developed according to the enhanced chemiluminescence system (Supersignal West Dura, Pierce). The levels of these proteins were quantified with the luminescent image analyzer LAS 4000 (Fuji Film, Tokyo, Japan) and normalized to $\beta$-actin.

Statistical analysis. The data are presented as mean \pm SE. Statistical analysis was performed by GraphPad Prism 

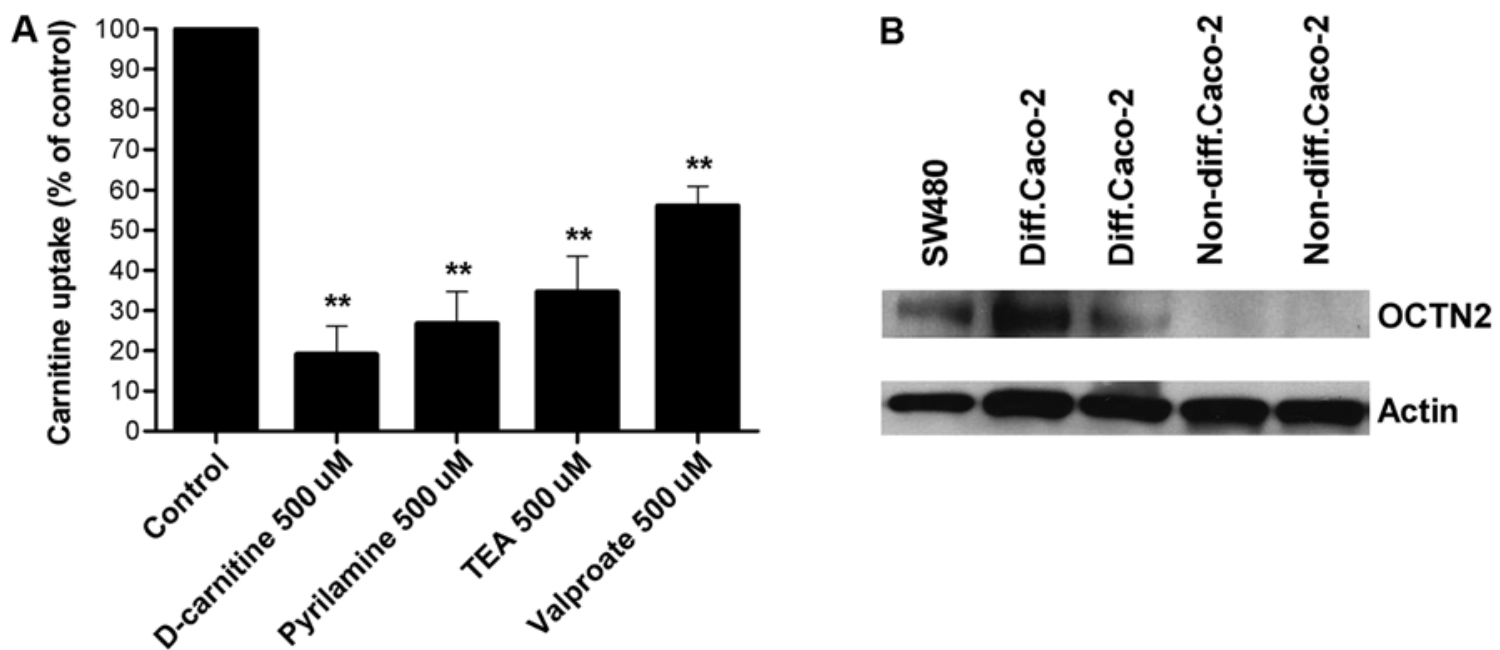

Figure 2. Carnitine transport by SW480 cells. Uptake of $50 \mathrm{nM} \mathrm{L-}\left[{ }^{3} \mathrm{H}\right]$-carnitine was measured at $37^{\circ} \mathrm{C}$ for $30 \mathrm{~min}$ in $\mathrm{Krebs}-\mathrm{Ringer}$ phosphate buffer at pH 7.4 in the presence of $500 \mu \mathrm{M}$ of OCTN2 inhibitors: D-carnitine, pyrilamine, TEA and valproate (A), and immunolocalization of OCTN2 by western blotting (B) using specific antibodies. After $70-90 \%$ of confluence, cells were maintained at $37^{\circ} \mathrm{C}$ in a $95 \%$ air $-5 \% \mathrm{CO}_{2}$ atmosphere. Cell homogenates were prepared for protein electrophoresis, as described in Materials and methods. After protein migration, blotting and addition of antibodies, the antigen-antibody complexes were revealed by using an enhanced chemiluminescence detection method. Each value represents the mean \pm SE of three separate experimentations. ${ }^{* *} \mathrm{p}<0.01$.

Software (San Diego, CA, USA). One-way ANOVA (Dunnett's multiple comparison test) was used for group analysis. For continuous variables, the Mann-Whitney non-parametric test was employed. A p-value of $<0.05$ was considered statistically significant.

\section{Results}

Carnitine uptake in colon cancer cells. In order to determine whether carnitine enhances the anticancer effect of butyrate in SW480, we first evaluated the capacity of this cell line to transport carnitine; we then determined the transport characteristics of carnitine into SW480 cells.

Carnitine uptake by confluent SW480 cells was compared to that by differentiated and non-differentiated Caco- 2 cells. We used a low carnitine concentration as classically employed to carry out transport studies (12-17); higher concentrations were tested as well. After 30-min incubation of $100 \mathrm{nM}$ of $\mathrm{L}-\left[{ }^{3} \mathrm{H}\right]$-carnitine, the transport by SW480 cells was 8 and 12 times higher $(\mathrm{p}<0.01)$ than that by differentiated and non-differentiated Caco-2 cells (Fig. 1A). Similarly, after 30 -min incubation of $5 \mathrm{mM} \mathrm{L}-\left[{ }^{3} \mathrm{H}\right]$-carnitine, the transport by SW480 cells was significantly higher $(\mathrm{p}<0.05)$ than that by differentiated and non-differentiated Caco-2 cells (Fig. 1B).

The SW480 uptake of $\mathrm{L}-\left[{ }^{3} \mathrm{H}\right]$-carnitine as a function of time was appreciable and linear with time $(\mathrm{r}=0.97)$, reaching an equilibrium at $\sim 180 \mathrm{~min}$ with $3.91 \mathrm{pmol} / \mathrm{mg}$ protein (Fig. 1C). L- $\left[{ }^{3} \mathrm{H}\right]-$ carnitine uptake by SW480 cells diminished significantly $(\mathrm{p}<0.05)$ when the luminal $\mathrm{Na}^{+}$concentration was reduced, and inhibited significantly $(\mathrm{p}<0.05)$ when the $\mathrm{Na}^{+}$ was completely iso-osmotically substituted by $\mathrm{K}^{+}$, achieved by adding $\mathrm{KCl}$ to the transport buffer (Fig. 1D). These results suggest that carnitine transport is $\mathrm{Na}^{+}$-coupled in SW480.

The ability of SW480 cells to transfer high concentrations of carnitine (5 mM) (Fig. 1B) suggests the potential involvement of another transporter, with lower affinity. To verify whether carnitine is transported by $\mathrm{ATB}^{0,+}$, a $\mathrm{Cl}^{-}$-coupled amino acid transporter, we examined the influence of $\mathrm{Cl}$ on carnitine uptake. $\mathrm{Cl}^{-}$depleted uptake buffer was used, replacing it with sodium gluconate. Removal of $\mathrm{Cl}^{-}$from the uptake buffer significantly reduced $(\mathrm{p}<0.05)$ the transport of carnitine, illustrating the effect of $\mathrm{Cl}^{-}$on this system (Fig. 1D), suggesting a possible role of transport by $\mathrm{ATB}^{0,+}$. To confirm involvement of $\mathrm{ATB}^{0,+}$, we investigated the effect of known amino acid substrates of $\mathrm{ATB}^{0,+}$ on carnitine transport. Neither low $(500 \mu \mathrm{M})$ nor high concentrations $(1 \mathrm{mM})$ of tryptophan, glycine or lysine significantly inhibited carnitine transport in SW480 cells (Fig. 1E). Taken together, these results suggest that there is a lack of involvement of $\mathrm{ATB}^{0++}$ in this transport system.

We then performed kinetic studies to determine the $\mathrm{K}_{\mathrm{m}}$ value for carnitine. At $50 \mathrm{nM} \mathrm{L}-\left[{ }^{3} \mathrm{H}\right]$-carnitine, uptake appears to be mediated by a membrane transporter with a high affinity for carnitine $\left(\mathrm{K}_{\mathrm{m}} \sim 4.3 \mu \mathrm{M}\right)$. This value, in the same range as the reported $\mathrm{K}_{\mathrm{m}}$ of OCTN2 (18), further supports the involvement of this transporter in carnitine uptake of by SW480 cells. An Eadie-Hofstee plot was then examined and the curve was compatible with a model involving 2 transporters (results not shown). At higher concentrations of carnitine, the $\mathrm{K}_{\mathrm{m}}$ value was $\sim 0.7 \mathrm{mM}$, suggesting that carnitine was also transported by a low affinity transporter.

Effect of inhibitors on carnitine transport by SW480 cells. The ability of specific drugs, known to interact with OCTN2, to inhibit carnitine transport was then investigated (Fig. 2A). D-carnitine, pyrilamine, TEA, and valproate all inhibited carnitine transport by SW480 cells (inhibition 40-80\%).

Western blot analysis of OCTN2. The next step was to confirm the role of OCTN2 in carnitine uptake by western blot analysis. Cell lysates were probed using polyclonal antibodies. Western blot analysis revealed a protein with an apparent molecular weight of $67 \mathrm{kDa}$ labeled by the mouse OCTN2-specific antibody in SW480 cells and in differentiated Caco-2 cells. 

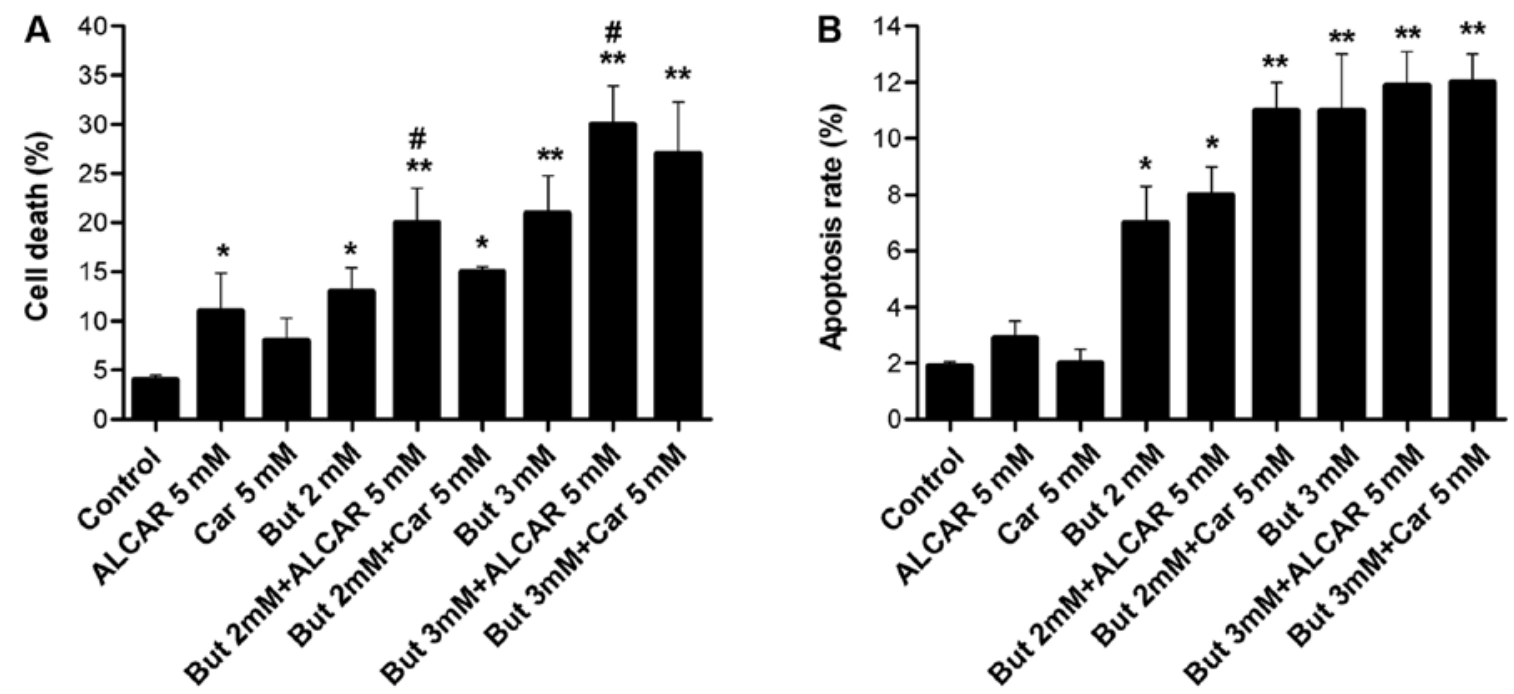

Figure 3. Effect of butyrate, carnitine and ALCAR on SW480 cell death (A) and apoptosis (B). Confluent SW480 were stimulated in the absence (control) or presence of butyrate $(2$ and $3 \mathrm{mM})$, carnitine $(5 \mathrm{mM})$, ALCAR $(5 \mathrm{mM})$ or butyrate in combination with carnitine or ALCAR, for 48 h. Cell death was quantified by flow cytometric assay using propidium iodide uptake. For apoptosis, cells were fixed in cold methanol and cleaved cytokeratin 18 was labeled by successive incubations with M30 CytoDEATH antibody and anti-mouse-Ig-fluorescein antibody. Fluorescent cleaved cytokeratin was monitored by flow cytometry. Results are expressed as percentage of cell death and values represent mean \pm SE for six experiments, each in duplicate. ${ }^{*}$ p $<0.05$ or ${ }^{* *}$ p $<0.01$ vs control and $" \mathrm{p}<0.05$ vs butyrate alone.
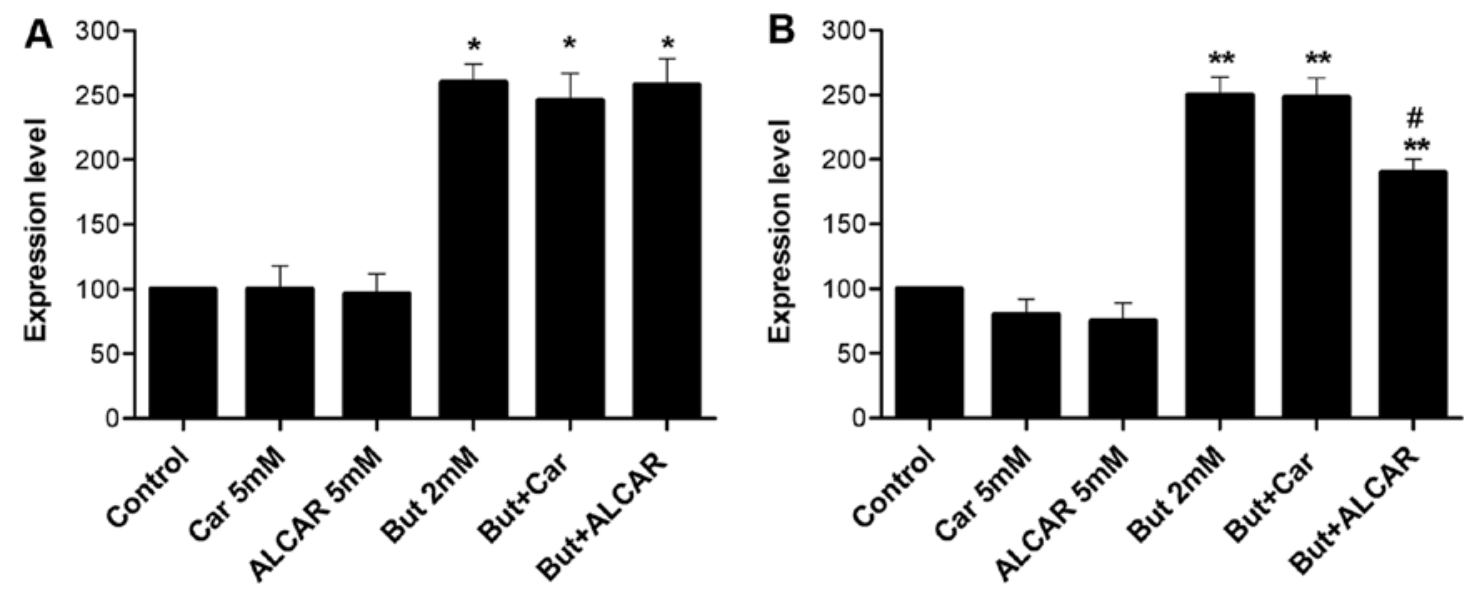

Figure 4. Effect of butyrate, carnitine and ALCAR on histone H4 acetylation (A) and p21 expression (B). After 48-h incubation in the absence or presence of butyrate, carnitine or ALCAR, SW480 cell lysates were analyzed by western blotting for histone H4 acetylation and p21 protein, then developed according to the enhanced chemiluminescence system. Each column is the mean \pm SE of three experiments. ${ }^{*} \mathrm{p}<0.05$ or ${ }^{* *} \mathrm{p}<0.01$ vs control and ${ }^{\#} \mathrm{p}<0.05$ vs butyrate alone.

No bands were detected in non-differentiated Caco-2 cells (Fig. 2B).

Cell death and apoptosis. The effects of butyrate (2 or $3 \mathrm{mM})$ alone or combined with carnitine $(5 \mathrm{mM})$ or ALCAR $(5 \mathrm{mM})$ on SW480 cell death were examined after $48 \mathrm{~h}$ of incubation. SW480 colon cancer cell death was significantly increased by 2 and $3 \mathrm{mM}$ butyrate alone $(\mathrm{p}<0.01, \mathrm{p}<0.05)$, as well as by ALCAR alone $(\mathrm{p}<0.05)$. The carnitine ester ALCAR potentiated the effects of butyrate, as cell mortality increased $(\mathrm{p}<0.05)$. However, addition of carnitine did not have a significant effect on SW480 cell death (Fig. 3A).

The results in Fig. 3A show that butyrate alone (2-3 mM) increased apoptosis fourfold after $48 \mathrm{~h}$, while carnitine and ALCAR alone $(5 \mathrm{mM})$ had no effect. The combination of butyrate and carnitine or ALCAR slightly induced apoptotic effect after $48 \mathrm{~h}$, but the difference was not statistically different when compared to butyrate alone (Fig. 3B).

Western blot analysis of proteins implicated in cell cycle control and apoptosis. To verify the mechanisms of the action of ALCAR on SW480 cells, changes in proteins implicated in cell cycle progression, apoptosis, as well as acetylation of histone proteins were measured. Butyrate alone induced significant changes in all the proteins studied, while carnitine and ALCAR had no significant effect.

Most colorectal cancers have mutations of the APC gene, allowing nuclear translocation of dephosphorylated $\beta$-catenin and upregulation of target genes, such as survivin and cyclin D1.

Butyrate alone downregulated dephospho- $\beta$-catenin and increased acetylated histone H4 levels (2.6-fold, $\mathrm{p}<0.01)$. 

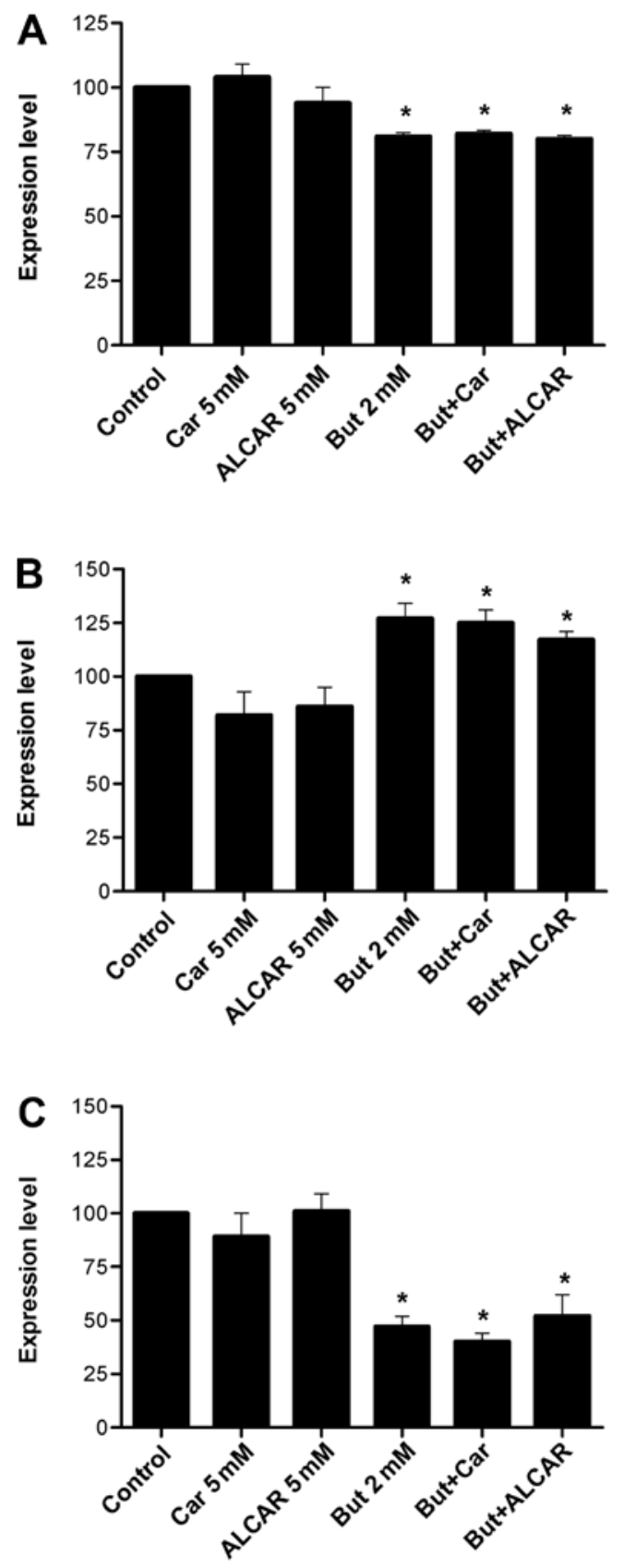

Figure 5. Effect of butyrate, carnitine and ALCAR on dephosphorylated $\beta$-catenin (A) and its target genes, survivin (B) and cyclin (C). After 48-h incubation in the absence or presence of butyrate $(2 \mathrm{mM})$, carnitine or ALCAR $(5 \mathrm{mM})$, SW480 cell lysates were analyzed by western blotting for dephosphorylated $\beta$-catenin, survivin and cyclin proteins, then developed according to the enhanced chemiluminescence system. Each column is the mean $\pm \mathrm{SE}$ of three experiments. ${ }^{*} \mathrm{p}<0.05$ vs control.

When it was combined with carnitine or ALCAR, the levels of these proteins were not affected (Figs. 4A and 5A). ALCAR alone induced a $20 \%$ decrease in p21 (p<0.05; Fig. 4B). At butyrate concentrations of $2 \mathrm{mM}$, carnitine consistently decreased survivin levels (Fig. 5C). No change was observed in cyclin D1 levels (Fig. 5B).

During apoptosis, caspases cleave poly(ADP-ribose) polymerase (PARP). Butyrate increased the level of cleaved PARP (5.9-fold), whereas it was not observed in response to carnitine or ALCAR (Fig. 6A).

\section{Discussion}

Free carnitine, ALCAR and others carnitine acyl esters offer protection from oxidative damage (19-21) by acetylating membrane proteins (22), removing long-chain acyl CoAs from cell membranes (23) and by scavenging free radicals (24). Recent studies investigated by Huang et al, have shown that carnitine inhibits cancer cell growth in vivo and in vitro by increasing histone acetylation, inducing accumulation of acetylated histones and by directly inhibiting HDAC I/II activities (25). ALCAR, sharing many of the same beneficial properties as carnitine, is considered to be more advantageous as a nutriceutical to enhance the effects of chemotherapy (26). ALCAR provides a source of acetyl groups that could be used for the acetylation of proteins involved in cellular response. Studies have shown that acetyl-L-carnitine has free radical scavenging activity protecting against hydroxyl free radicals, inhibits oxidant-induced DNA single-strand breaks and acts as a histone hyperacetylating agent (27-32). A study by Pisano et al (33) reported significant anti-metastatic activity of ALCAR in wild-type p53 tumors and a significant synergistic effect with a histone deacetylase inhibitor.

We previously reported that carnitine has a beneficial impact on butyrate induced colon cancer cell death in Caco- 2 cells $(5,11)$. The mechanisms by which carnitine modulates butyrateinduced cancer cell death have not been elucidated. One hypothesis is that carnitine may affect butyrate availability and metabolism in colon cancer cells. In the course of our experiments, we noted that carnitine transport was limited in Caco-2 cells, a cell line that express negligible levels of OCTN2, a key carnitine transporter (12). One of the first aims of the present study was to identify a human colon cancer cell line with more efficient carnitine transport, in order to determine if the beneficial effects of carnitine and ALCAR would be increased.

We identified SW480 cells as a colon cancer cell line with high carnitine uptake (Fig. 1A-C) and express OCTN2 (Fig. 2B). Carnitine transport was significantly reduced $(\mathrm{p}<0.05)$ when the luminal $\mathrm{Na}_{+}$concentration was reduced or depleted by substituting $\mathrm{KCl}$ for $\mathrm{NaCl}$ (Fig. 1D). Uptake was also inhibited significantly $(\mathrm{p}<0.05)$ in $\mathrm{Cl}^{-}$-depleted buffer (Fig. 1D). These results are consistent with $\mathrm{Na}^{+}$-dependent carrier-mediated system for L-carnitine in SW480 cells.

At low carnitine concentrations typically used to study transport, $\left[{ }^{3} \mathrm{H}\right]$-carnitine uptake by SW480 cells was 8 and 12 times higher than that in differentiated and non-differentiated Caco-2 cells, respectively (Fig. 1A-C). These differences were attenuated at higher concentrations. At a carnitine concentration of $5 \mathrm{mM}$, uptake by SW480 cells was 6 times higher than that by non-differentiated Caco-2 cells (Fig. 1A and $\mathrm{B}$ ). At $50 \mathrm{nM}$ concentration, carnitine transport appeared to be mediated by a high affinity membrane transporter with a $\mathrm{K}_{\mathrm{m}} \sim 4.3 \mu \mathrm{M}$. This in the same range as that reported for OCTN2 (18). Furthermore, carnitine transport by SW480 cells was found to be $\mathrm{Na}^{+}$-dependent (Fig. 1D). We also examined the effect of $\mathrm{D}$-carnitine and certain cationic drugs known to inhibit L-carnitine transport by OCTN2 $(12,34,35)$. Pyrilamine, TEA and valproate, competitively inhibit carnitine transport (Fig. 2A).

Western blot experiments using an OCTN2-specific antibody confirmed the presence of OCTN2 in SW480 cells 

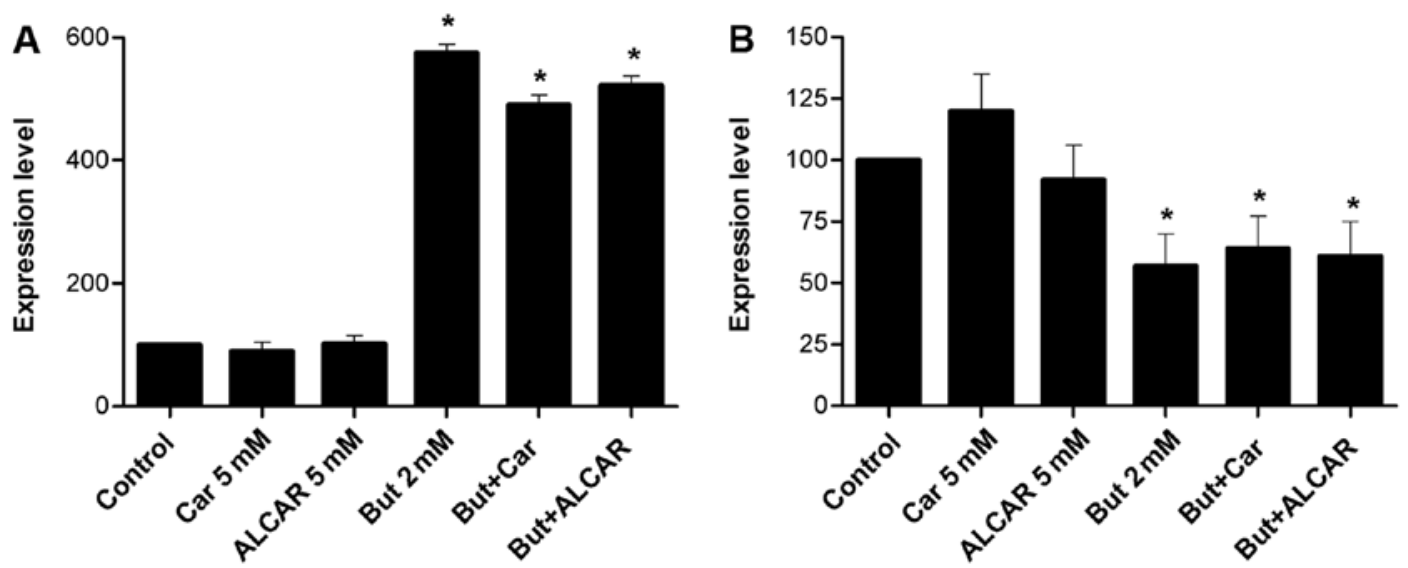

Figure 6. Western blot analysis of SW480 cell lysates for PARP (A) and for the anti-apoptotic protein BCL-X $\mathrm{L}_{\mathrm{L}}$ (B). Cells were pretreated $48 \mathrm{~h}$ with or without butyrate $(2$ and $3 \mathrm{mM})$, carnitine or ALCAR $(5 \mathrm{mM})$. After treatment, cell lysates were prepared and levels of the protein expression of PARP and BCL-X were analyzed by western blotting. Each column is the mean \pm SE of three experiments. * $\mathrm{p}<0.05$ vs control.

(Fig. 2B). The molecular size of the detected band is close to the estimated size $(63 \mathrm{kDa})$ of OCTN2 $(12,17,36)$. As we reported previously (11), differentiated Caco- 2 cells (a model of small intestinal absorptive cells) express OCTN2 (Fig. 2B), whereas non-differentiated Caco-2 cells do not, in keeping with the absence of transport of L-carnitine in malignant Caco-2 cells. Recent studies $(30,37,38)$ have shown that OCTN2 is also involved in the transport of ALCAR. This suggests that ALCAR uptake by SW480 will potentially enhance the synergistic effect of butyrate on these cancer cells.

An Eadie-Hofstee plot was compatible with a model involving 2 transporters in SW480 cells. At higher doses, carnitine was transported by a low affinity $(\sim 0.7 \mathrm{mM})$ transporter. Uptake at $5 \mathrm{mM}$ carnitine was also $\mathrm{Na}^{+}$-dependent; as well as Cl-dependent, implicating the $\mathrm{ATB}^{0,+}$ transporter $(39,40)$. At low concentration, carnitine transport in SW480 cells was not inhibited by tryptophane, glycine or lysine, amino acid substrates of $\mathrm{ATB}^{0,+}$. Studies at high concentration were physiologically irrelevant due to the high concentrations $(>100$-fold excess) required to inhibit carnitine transport. There are no suitable commercially available antibodies specific for $\mathrm{ATB}^{0,+}$ to carry out western blot analyses. SW480 cells were found to express low levels of ATB $^{0,+}$ by RT-PCR (41). Nevertheless, the transport characteristics observed are not sufficient to eliminate members of the OCTN family, and identify $\mathrm{ATB}^{0,+}$ as the transporter involved in carnitine transport at high concentrations.

Once we identified the relatively high carnitine uptake by SW480, we proceeded with experiments to determine the effect of carnitine and ALCAR alone or with butyrate, on inducing apoptosis and cell death in these colon cancer cells. Butyrate alone $(2$ and $3 \mathrm{mM})$ reduced cell growth $(\mathrm{p}<0.05$ and $\mathrm{p}<0.01)$. ALCAR but not carnitine significantly increased SW480 cell death $(10.2$ vs. $4.6 \%, \mathrm{p}<0.05)$. Cells treated with a combination of butyrate and ALCAR significantly increased the mortality of cancer cells ( $p<0.05$, Fig. 3A).

We next examined if the same combined treatment induced apoptosis. Butyrate alone induced apoptosis in SW480 cells. Carnitine and ALCAR increased butyrate-induced apoptosis by $8-14 \%$, although the difference failed to reach statistical significance. ALCAR (10 mM) was shown to enhance the p53 activation and sensitize several cancer cells lines to cisplatin. However, it was not effective in sensitizing PC-3 and the colon cancer cells SW620 and HT-29, in which p53 is null or mutated (33). Our study is therefore the first one to show that ALCAR can enhance cell death induced by an anticarcinogenic compound in cancer cells with mutated p53. The results concerning apoptosis (Fig. 3B) and PARP suggest the involvement of caspase-independent pathways in this antitumor effect.

Epigenic alterations of histone and non-histone proteins are a central event in the initiation and progression of cancer. Histone deacetylase inhibitors such as butyrate can reactivate the transcription of silenced genes and restore normal cellular growth and differentiation (6). We therefore studied the effect of butyrate, carnitine and ALCAR on histone acetylation. Butyrate increased histone 4 acetylation while carnitine or ALCAR had no effect. When used in combination with butyrate, carnitine and ALCAR did not induce changes compared to butyrate alone. Thus, despite the fact that uptake of ALCAR can supply the cell with acetyl groups (42), acetylation of histones was not increased (Fig. 4A). This may be due to the existence of compartmented pools of acetyl inside the cells and limited access to the nucleus. Alternatively, the efficiency of this transfer that relies on the activity of nuclear carnitine/acylcarnitine translocase might be lower in cancer cells. Another explanation might be that there is already a good supply of intracellular acetyl groups that is minimally affected by exogenous carnitine.

We undertook the study of key proteins implicated in cell cycle progression and apoptosis (p21, cyclin D1, survivin, $\mathrm{Bcl}-\mathrm{X}_{\mathrm{L}}$ ). The $\mathrm{p} 21$ protein is a cyclin-dependent kinase inhibitor that mediates cell cycle progression through G1 phase arrest. Expression of p21 coincides with hyperacetylation of histones $\mathrm{H} 3$ and $\mathrm{H} 4$ in the promoter region. We showed that butyrate induced p21 expression, consistent with other studies $(43,44)$. Although the role of p21 on cell cycle progression is well established, controversy exists whether p21 is pro- or anti-apoptotic. p21 is an important downstream effector of p53-signaling. SW480 cells contain a mutated form of p53, presumably without pro-apoptotic potential, but with some transcriptional activity such as the ability to induce p21 (45). Paradoxically, p21 has been shown to promote apoptosis as 
well as to protect tumor cells from apoptosis, particularly when DNA-damaging agents are used. Enhanced p21 expression was associated with increased apoptosis and protection in colon carcinogenesis in rats provided fish oil-supplemented diets. In contrast enhanced p21 led to higher levels of aberrant crypt formation in rats provided corn-oil supplemented diet (43). We observed that ALCAR decreased butyrate-induced p21 upregulation (Fig. 4B).

We furthermore analyzed the capacity of carnitine/ALCAR to alter $\beta$-catenin expression in SW480 cells. Most colorectal cancers have mutations of the adenomatous polyposis coli (APC) gene that stabilize $\beta$-catenin, allowing nuclear translocation and upregulation of $\beta$-catenin target genes, notably survivin, cyclin D1 and c-myc (46). Phosphorylation directs $\beta$-catenin towards degradation and non-phosphorylated $\beta$-catenin translocates to the nucleus. Levels of dephosphorylated $\beta$-catenin were assessed following treatment of SW480 with butyrate. Butyrate downregulated dephospho- $\beta$-catenin by $20 \%$, while carnitine and ALCAR had no appreciable effect (Fig. 5A).

Cyclin D1 is a downstream molecule of the $\beta$-catenin pathway that plays an important role in cell cycle progression as it drives the G1/S phase transition (47). Cyclin D1 levels were $27 \%$ increased by butyrate (Fig. $5 \mathrm{~B}$ ). This increase is distinctive to SW480 cells, as cyclin D1 level is decreased by butyrate in Caco-2 and HT-29 colon cancer cells (48). Cyclin D1 expression was decreased by $19-20 \%$ when SW480 cells were treated with carnitine and ALCAR. Combined treatment with butyrate resulted in levels similar to butyrate treatment alone. Therefore, although single agents have opposite effects on cyclin D1, the butyrate effect predominates when the compounds were provided together. Increased cyclin D1 upon butyrate treatment appears to contradict its effect on the Wnt/ $\beta$-catenin pathway. Similar induction of cyclin D1 despite inhibition of proliferation in SW480 cells was already observed. It was postulated that combined c-Myc reduction and p21 induction had more determinant effect than cyclin D1 on cell cycle progression (45).

Survivin is an anti-apoptotic protein frequently upregulated in cancer cells. Survivin levels were markedly decreased by butyrate (50\% reduction) using a lower dose of butyrate $(2 \mathrm{mM}$ ), as a $3-\mathrm{mM}$ dose decreased survivin by $>80 \%$ (not shown). These data are congruent with other findings indicating the growth-inhibitory action of butyrate by decreasing survivin expression in Caco-2 cells and by increase caspase-3 activity, cleavage of PARP and caspase-8 (49). When cells were treated by carnitine, a trend towards decreased survivin levels ( $88 \%$ of basal levels) was observed. The trend was maintained when carnitine was added to butyrate (55\% reduction vs. $50 \%$ ). However, these changes did not reach statistical significance due to variability between repeat experiments and the low overall magnitude (Fig. 5B).

Poly(ADP-ribose) polymerase (PARP) is cleaved by caspases during apoptosis and is therefore a marker of caspasedependent apoptosis (49). As expected, PARP cleavage was increased by butyrate (5.9-fold). This was not modified by carnitine or ALCAR (Fig. 6A). Bcl- $\mathrm{X}_{\mathrm{L}}$ is an anti-apoptotic protein that is often upregulated in cancer cells. Levels of Bcl- $X_{\mathrm{L}}$ were decreased by butyrate, whereas carnitine and ALCAR had no effect on its expression (Fig. 6B).
In conclusion, our findings suggest that butyrate and acetylcarnitine are potentially beneficial anticarcinogenic nutrients that inhibit colon cancer cell survival. The combination of both nutrients may have superior anticarcinogenic properties than the single agents alone. Recently, the efficacy of carnitine and acyl-carnitine to slow down the growth of colon cancer was reported in a murine model using the 1,2,-dimethylhydrazine (DMH)-induced colon carcinogenesis model (50). Further research in this area is needed to determine whether carnitines may be useful in the human setting.

\section{Acknowledgements}

This study was supported by a research grant (IQ, EGS) co-funded by the Dairy Farmers of Canada and the National Science and Engineering Council of Canada (NSERC). Funding for equipment was provided by the Canadian Foundation for Innovation (EGS). Funding support for salary was awarded by a Canada Research Chair in Immune Mediated Gastrointestinal Disorders (EGS), the Bruce Kaufman Chair at McGill (EGS) and the J.A. de Sève Research Chair in Nutrition (EL).

\section{References}

1. Hamer HM, Jonkers D, Venema K, Vanhoutvin S, Troost FJ and Brummer RJ: The role of butyrate on colonic function. Aliment Pharmacol Ther 27: 104-119, 2008.

2. Macfarlane GT and Macfarlane S: Fermentation in the human large intestine: its physiologic consequences and the potential contribution of prebiotics: J Clin Gastroenterol 45 (Suppl): S120-S127, 2011.

3. Clarke JM, Young GP, Topping DL, Bird AR, Cobiac L, Scherer BL, Winkler JG and Lockett TJ: Butyrate delivered by butyrylated starch increases distal colonic epithelial apoptosis in carcinogen-treated rats. Carcinogenesis 33: 197-202, 2012.

4. Wang HG, Huang XD, Shen P, Li LR, Xue HT and Ji GZ: Anticancer effects of sodium butyrate on hepatocellular carcinoma cells in vitro. Int J Mol Med 31: 967-974, 2013.

5. Ruemmele FM, Dionne S, Qureshi I, Sarma DS, Levy E and Seidman EG: Butyrate mediates Caco-2 cell apoptosis via upregulation of pro-apoptotic BAK and inducing caspase-3 mediated cleavage of poly-(ADP-ribose) polymerase (PARP). Cell Death Differ 6: 729-735, 1999.

6. Berni Canani R, Di Costanzo M and Leone L: The epigenetic effects of butyrate: potential therapeutic implications for clinical practice. Clin Epigenetics 4: 4, 2012.

7. Reuter SE and Evans AM: Carnitine and acylcarnitines: pharmacokinetic, pharmacological and clinical aspects. Clin Pharmacokinet 51: 553-572, 2012.

8. Steiber A, Kerner J and Hoppel CL: Carnitine: a nutritional, biosynthetic, and functional perspective. Mol Aspects Med 25: 455-473, 2004.

9. Hoppel C: The role of carnitine in normal and altered fatty acid metabolism. Am J Kidney Dis 41 (Suppl 4): S4-S12, 2003.

10. Dionne S, Elimrani I, Roy MJ, Qureshi IA, Sarma DR, Levy E and Seidman EG: Studies on the chemopreventive effect of carnitine on tumorigenesis in vivo, using two experimental murine models of colon cancer. Nutr Cancer 64: 1279-1287, 2012.

11. Roy MJ, Dionne S, Marx G, Qureshi I, Sarma D, Levy E and Seidman EG: In vitro studies on the inhibition of colon cancer by butyrate and carnitine. Nutrition 25: 1193-1201, 2009.

12. Elimrani I, Lahjouji K, Seidman E, Roy MJ, Mitchell GA and Qureshi I: Expression and localization of organic cation/carnitine transporter OCTN2 in Caco-2 cells. Am J Physiol Gastrointest Liver Physiol 284: G863-G871, 2003.

13. Xu MH and Zhang GY: Effect of indomethacin on cell cycle proteins in colon cancer cell lines. World J Gastroenterol 11: 1693-1696, 2005.

14. Zhao L, Liu L, Wang S, Zhang YF, Yu L and Ding YQ: Differential proteomic analysis of human colorectal carcinoma cell lines metastasis-associated proteins. J Cancer Res Clin Oncol 133: 771-782, 2007. 
15. McCloud E, Ma TY, Grant KE, Mathis RK and Said HM: Uptake of L-carnitine by a human intestinal epithelial cell line, Caco-2. Gastroenterology 111: 1534-1540, 1996.

16. Koizumi A, Nozaki J, Ohura T, Kayo T, Wada Y, Nezu J, Ohashi R, Tamai I, Shoji Y, Takada G, et al: Genetic epidemiology of the carnitine transporter OCTN2 gene in a Japanese population and phenotypic characterization in Japanese pedigrees with primary systemic carnitine deficiency. Hum Mol Genet 8: 2247-2254, 1999.

17. Lahjouji K, Elimrani I, Lafond J, Leduc L, Qureshi IA and Mitchell GA: L-Carnitine transport in human placental brushborder membranes is mediated by the sodium-dependent organic cation transporter OCTN2. Am J Physiol Cell Physiol 287: C263-C269, 2004.

18. Ohashi R, Tamai I, Nezu Ji J, Nikaido H, Hashimoto N, Oku A, Sai Y, Shimane M and Tsuji A: Molecular and physiological evidence for multifunctionality of carnitine/organic cation transporter OCTN2. Mol Pharmacol 59: 358-366, 2001.

19. Virmani A and Binienda Z: Role of carnitine esters in brain neuropathology. Mol Aspects Med 25: 533-549, 2004

20. Chang B, Nishikawa M, Nishiguchi S and Inoue M: L-carnitine inhibits hepatocarcinogenesis via protection of mitochondria. Int J Cancer 113: 719-729, 2005.

21. Zhang R, Zhang H, Zhang Z, Wang T, Niu J, Cui D and Xu S Neuroprotective effects of pre-treatment with l-carnitine and acetyl-L-carnitine on ischemic injury in vivo and in vitro. Int J Mol Sci 13: 2078-2090, 2012

22. Pettegrew JW, Levine J and McClure RJ: Acetyl-L-carnitine physical-chemical, metabolic, and therapeutic properties: relevance for its mode of action in Alzheimer's disease and geriatric depression. Mol Psychiatry 5: 616-632, 2000.

23. Branca D, Toninello A, Scutari G, Florian M, Siliprandi N, Vincenti E and Giron GP: Involvement of long-chain acyl CoA in the antagonistic effects of halothane and L-carnitine on mitochondrial energy-linked processes. Biochem Biophys Res Commun 139: 303-307, 1968.

24. Gulcin I: Antioxidant and antiradical activities of L-carnitine. Life Sci 78: 803-811, 2006.

25. Huang H, Liu N, Guo H, Liao S, Li X, Yang C, Liu S, Song W, Liu C, Guan L, et al: L-carnitine is an endogenous HDAC inhibitor selectively inhibiting cancer cell growth in vivo and in vitro. PLoS One 7: e49062, 2012.

26. Pisano C, Pratesi G, Laccabue D, Zunino F, Lo Giudice P, Bellucci A, Pacifici L, Camerini B, Vesci L, Castorina M, et al: Paclitaxel and cisplatin-induced neurotoxicity: a protective role of acetyl-L-carnitine. Clin Cancer Res 9: 5756-5767, 2003.

27. Pascale E, Battiloro E, Cimino Reale G, Pietrobono R, Pomponi MG, Chiurazzi P, Nicolai R, Calvani M, Neri G and D'Ambrosio E: Modulation of methylation in the FMR1 promoter region after long term treatment with L-carnitine and acetyl-Lcarnitine. J Med Genet 40: e76, 2003.

28. Rosca MG, Lemieux H and Hoppel CL: Mitochondria in the elderly: is acetylcarnitine a rejuvenator? Adv Drug Deliv Rev 61: 1332-1342, 2009

29. Tabolacci E, Pietrobono R, Moscato U, Oostra BA, Chiurazzi P and Neri G: Differential epigenetic modifications in the FMR1 gene of the fragile $X$ syndrome after reactivating pharmacological treatments. Eur J Hum Genet 13: 641-648, 2005.

30. Loots DT, Mienie LJ, Bergh JJ and Van der Schyf CJ: AcetylL-carnitine prevents total body hydroxyl free radical and uric acid production induced by 1-methyl-4-phenyl-1,2,3,6-tetrahydropyridine (MPTP) in the rat. Life Sci 75: 1243-1253, 2004.

31. Boerrigter ME, Franceschi C, Arrigoni-Martelli E, Wei JY and Vijg J: The effect of L-carnitine and acetyl-L-carnitine on the disappearance of DNA single-strand breaks in human peripheral blood lymphocytes. Carcinogenesis 14: 2131-2136, 1993.

32. Schinetti ML, Rossini D, Greco R and Bertelli A: Protective action of acetylcarnitine on NADPH-induced lipid peroxidation of cardiac microsomes. Drugs Exp Clin Res 13: 509-515, 1987.

33. Pisano C, Vesci L, Milazzo FM, Guglielmi MB, Fodera R, Barbarino M, D'Incalci M, Zucchetti M, Petrangolini G, Tortoreto M, et al: Metabolic approach to the enhancement of antitumor effect of chemotherapy: a key role of acetyl-Lcarnitine. Clin Cancer Res 16: 3944-3953, 2010.
34. Ohashi R, Tamai I, Yabuuchi H, Nezu JI, Oku A, Sai Y, Shimane $\mathrm{M}$ and Tsuji $\mathrm{A}$ : $\mathrm{Na}(+)$-dependent carnitine transport by organic cation transporter (OCTN2): its pharmacological and toxicological relevance. J Pharmacol Exp Ther 291: 7787-84, 1999.

35. Glube N, Closs E and Langguth P: OCTN2-mediated carnitine uptake in a newly discovered human proximal tubule cell line (Caki-1). Mol Pharm 4: 160-168, 2007.

36. Lahjouji K, Mitchell GA and Qureshi IA: Carnitine transport by organic cation transporters and systemic carnitine deficiency. Mol Genet Metab 73: 2872-2897, 2001.

37. Cano MM, Calonge ML and Ilundain AA: Expression of OCTN2 and OCTN3 in the apical membrane of rat renal cortex and medulla. J Cell Physiol 223: 451-459, 2010.

38. Tachikawa M, Takeda Y, Tomi M and Hosoya K: Involvement of OCTN2 in the transport of acetyl-L-carnitine across the inner blood-retinal barrier. Invest Ophthalmol Vis Sci 51: 430-436, 2010.

39. Nakanishi T, Hatanaka T, Huang W, Prasad PD, Leibach FH, Ganapathy ME and Ganapathy $\mathrm{V}$ : $\mathrm{Na}^{+}$- and $\mathrm{Cl}^{-}$-coupled active transport of carnitine by the amino acid transporter $\operatorname{ATB}(0,+)$ from mouse colon expressed in HRPE cells and Xenopus oocytes. J Physiol 532: 297-304, 2001.

40. Nakanishi T, Kekuda R, Fei YJ, Hatanaka T, Sugawara M, Martindale RG, Leibach FH, Prasad PD and Ganapathy V: Cloning and functional characterization of a new subtype of the amino acid transport system N. Am J Physiol Cell Physiol 281: C1757-C1768, 2001.

41. Karunakaran S, Umapathy NS, Thangaraju M, Hatanaka T, Itagaki S, Munn DH, Prasad PD and Ganapathy V: Interaction of tryptophan derivatives with SLC6A14 $\left(\mathrm{ATB}^{0,+}\right)$ reveals the potential of the transporter as a drug target for cancer chemotherapy. Biochem J 414: 343-355, 2008.

42. Madiraju P, Pande SV,Prentki M and Madiraju SR: Mitochondrial acetylcarnitine provides acetyl groups for nuclear histone acetylation. Epigenetics 4: 399-403, 2009.

43. Hu S, Dong TS, Dalal SR, Wu F, Bissonnette M, Kwon JH and Chang EB: et al: The microbe-derived short chain fatty acid butyrate targets miRNA-dependent $\mathrm{p} 21$ gene expression in human colon cancer. PLoS One 6: e16221, 2011.

44. Crim KC, Sanders LM, Hong MY, Taddeo SS, Turner ND, Chapkin RS and Lupton JR: Upregulation of $\mathrm{p} 21^{\text {Waf } 1 / \text { Cip }}$ expression in vivo by butyrate administration can be chemoprotective or chemopromotive depending on the lipid component of the diet. Carcinogenesis 29: 1415-1420, 2008

45. Hartman J, Edvardsson K, Lindberg K, Zhao C, Williams C, Strom A and Gustafsson JA: Tumor repressive functions of estrogen receptor beta in SW480 colon cancer cells. Cancer Res 69: 6100-6106, 2009

46. Bottomly D, Kyler SL, McWeeney SK and Yochum GS Identification of $\{$ beta\}-catenin binding regions in colon cancer cells using ChIP-Seq. Nucleic Acids Res: 5735-5745, 2010.

47. Ravichandran K, Velmurugan B, Gu M, Singh RP and Agarwal R: Inhibitory effect of silibinin against azoxymethaneinduced colon tumorigenesis in $\mathrm{A} / \mathrm{J}$ mice. Clin Cancer Res 16: 4595-4606, 2010.

48. Nepelska M, Cultrone A, Béguet-Crespel F, Le Roux K, Doré J, Arulampalam $\mathrm{V}$ and Blottière HM: Butyrate produced by commensal bacteria potentiates phorbol esters induced AP-1 response in human intestinal epithelial cells. PLoS One 7 e52869, 2012

49. Schwab M, Reynders V, Steinhilber D and Stein J: Combined treatment of Caco-2 cells with butyrate and mesalazine inhibits cell proliferation and reduces survivin protein level. Cancer Lett 273: 98-106, 2009.

50. Roscilli G, Marra E, Mori F, Di Napoli A, Mancini R, SerlupiCrescenzi O, Virmani A, Aurisicchio L and Ciliberto G: Carnitines slow down tumor development of colon cancer in the DMH-chemical carcinogenesis mouse model. J Cell Biochem 114: 1665-1673, 2013. 